\title{
Competition between two wetland macrophytes under different levels of sediment saturation
}

\author{
Feng LI, ${ }^{1,2 \#}$ Gang YANG, ${ }^{3 \#}$ Yonghong XIE,,${ }^{1,2 *}$ Xinsheng CHEN,,${ }^{1,2}$ Zhengmiao DENG,,${ }^{1,2}$ Jiayu HU ${ }^{1,2,4}$ \\ ${ }^{1}$ Key Laboratory of Agro-ecological Processes in Subtropical Region, Chinese Academy of Sciences, 410125 Hunan; ${ }^{2}$ Dongting Lake \\ Station for Wetland Ecosystem Research, Institute of Subtropical Agriculture, 410125 Changsha; ${ }^{3}$ Life Science and Engineering College, \\ Southwest University of Science and Technology, 621010 Mianyang; ${ }^{4}$ Graduate School of the Chinese Academy of Sciences, 100049 \\ Beijing, China \\ \#Both authors equally contributed to this work \\ *Corresponding author: yonghongxie@163.com
}

\begin{abstract}
Plant-plant interactions have been widely studied under various environmental conditions. However, in wetland ecosystems how plant interactions change in response to variation in sediment saturation remains largely unclear, even though different levels of sediment saturation play important roles in determining plant growth performance in wetland ecosystems. To this end, a competition experiment with two typical wetland species, Carex brevicuspis (neighbor plant) and Polygonum hydropiper (target plant), was conducted in a target-neighbor design. Two water levels $(0 \mathrm{~cm}$ and $-40 \mathrm{~cm}$ water levels representing waterlogged and drained sediments, respectively) and three neighbor plant densities (0 plants $\mathrm{m}^{-2}, 400$ plants $\mathrm{m}^{-2}$, and 1600 plants $\mathrm{m}^{-2}$ ) were tested in a factorial design. Biomass accumulation of $\mathrm{P}$. hydropiper decreased along with enhanced $\mathrm{C}$. brevicuspis density in the waterlogged treatment. However, in the drained treatment, biomass accumulation did not change under two C. brevicuspis densities. Above-ground relative neighbor effect index (ARNE) and relative neighbor effect index (RNE) of $\mathrm{C}$. brevicuspis on $\mathrm{P}$. hydropiper increased along with enhanced $\mathrm{C}$. brevicuspis density only under waterlogged conditions. The below-ground relative neighbor effect index (BRNE) was not affected at the different water level and density treatments. The below-ground mass fraction of $\mathrm{P}$. hydropiper was much higher in the waterlogged treatment than it was in the drained one, especially with no C. brevicuspis treatment. However, the leaf mass fraction displayed the opposite pattern. The longest root length of $\mathrm{P}$. hydropiper was much shorter under waterlogged treatment than under the drained treatment. These results suggest that the competition intensity of $\mathrm{C}$. brevicuspis to $\mathrm{P}$. hydropiper increased along with increasing $\mathrm{C}$. brevicuspis density only under waterlogged conditions. Moreover, this study also confirms that $\mathrm{P}$. hydropiper can acclimate to water stress mainly through modulating its root architecture, for example reducing the root system length or increasing the root mass fraction.
\end{abstract}

Key words: Sediment saturation gradient, stress-gradient hypothesis, interspecific competition, Carex brevicuspis, Polygonum hydropiper.

Received: May 2014. Accepted: February 2015.

\section{INTRODUCTION}

Plant-plant interactions, including negative (competition or interference), neutral, and positive (facilitation) relationships, have been a focal issue in plant community ecology for decades (Michalet et al., 2006; Brooker et al., 2008). Competition involves a struggle to preempt resources, such as light, water, and nutrients, which consequently limit plant growth and restrict species distribution ranges by reducing their available niche (Grime, 2001). Conversely, facilitation promotes plants growth and potentially extends the geographical range of species (Michalet et al., 2006).

Studies have confirmed that the direction and intensity of interactions varied significantly according to gradients of abiotic factors, neighbor characteristics, and target plant traits (Pennings, et al., 2003; Luo et al., 2010). Furthermore, these changes play important roles in maintaining vegetation structure and dynamics (Gebauer et al.,
2002; Armas and Pugnaire, 2005). The relationship between plant interactions and the environment has been summarized as the stress-gradient hypothesis (SGH), which suggests that a shift from net negative towards net positive interactions can take place moving from benign to harsh environments (Callaway et al., 2002). To date, this hypothesis is supported by various studies conducted in a wide variety of ecosystems and different environmental gradients (Callaway et al., 2002; Luo et al., 2010). However, other studies have failed to confirm this hypothesis (Pennings et al., 2003; Gross et al., 2010). Therefore, the generality of this hypothesis need to be further tested (Maestre et al., 2005; Lortie and Callaway, 2006).

Wetland vegetation, especially that growing in riverconnected lakes or floodplains, often experiences both drained and waterlogged sediment conditions (Grace, 1999; Pagter et al., 2005). Waterlogging could inhibit plant growth mainly due to the reduced oxygen availability and redox potential (Eh) in the sediment (Deegan et 
al., 2007; Li et al., 2011). Generally, plants can acclimatize to waterlogged conditions through various morphological adaptations, such as increased allocation to roots, decreased root length, and formation of aerenchyma (Loreti and Oesterheld, 1996; Lenssen et al., 2003; Xie et al., 2008). These adaptations allow plants to acclimatize to anaerobic conditions by increasing oxygen transport to roots or by reducing radial oxygen loss to the sediment (Luo and Xie, 2009). Moreover, these adaptations depend on the duration of waterlogging, variability in environmental factors (e.g., pore water oxygen and nutrient availability, redox potential) and, plant development (Ribaudo et al., 2011; Soana and Bartoli, 2014). Plant interactions under various abiotic factors have been widely studied, and include water availability (Luo et al., 2010; Weigelt et al., 2000; Zhang et al., 2014), sedimentation (Franks and Peterson, 2003), and salinity (Mesléard et al., 1993). However, the mechanisms of plant-plant interactions differ significantly under vary environmental stresses and require further studies.

The aim of this experiment was to elucidate how the intensity of interspecific competition changes in response to drained and waterlogged sediment conditions. To this end, at Dongting Lake, a competition experiment between the two local dominant wetland species (Carex brevicuspis C. B. Clarke and Polygonum hydropiper Linn) was conducted using a target-neighbor design. P. hydropiper, as the target plant, was grown at two water levels and three $C$. brevicuspis densities (under six different experimental treatments). Biomass accumulation, above-ground relative neighbor effect index (ARNE), below-ground relative neighbor effect index (BRNE), relative neighbor effect index (RNE) of C. brevicuspis on P. hydropiper, biomass allocation and the longest root length of $P$. hydropiper were investigated to test the following hypotheses: i) the growth performance of $P$. hydropiper was significantly inhibited by waterlogged treatments. Moreover, the longest root length would be reduced but root mass fraction would be increased in the waterlogged treatment; ii) higher neighbor density would inhibit the growth performance of $P$. hydropiper; iii) growth performance and competition intensity would be altered when $P$. hydropiper was subjected to competition and waterlogged conditions simultaneously.

\section{METHODS}

\section{Study area}

Dongting Lake ( $\left.28^{\circ} 30^{\prime}-30^{\circ} 20^{\prime} \mathrm{N}, 111^{\circ} 40^{\prime}-113^{\circ} 10^{\prime} \mathrm{E}\right)$, the second largest freshwater lake in China with an area of $2620 \mathrm{~km}^{2}$, is located in the northern Hunan Province in a basin south of the Yangtze River, to which it is connected by three distributary channels (Pan et al., 2014; Fig. 1). The mean annual temperature in this wetland is $16.4-17^{\circ} \mathrm{C}$, with the lowest (i.e., $3.9-4.5^{\circ} \mathrm{C}$ ) and highest (i.e., $28.6-29.1^{\circ} \mathrm{C}$ ) temperatures in January and July, respectively. Annual pre-

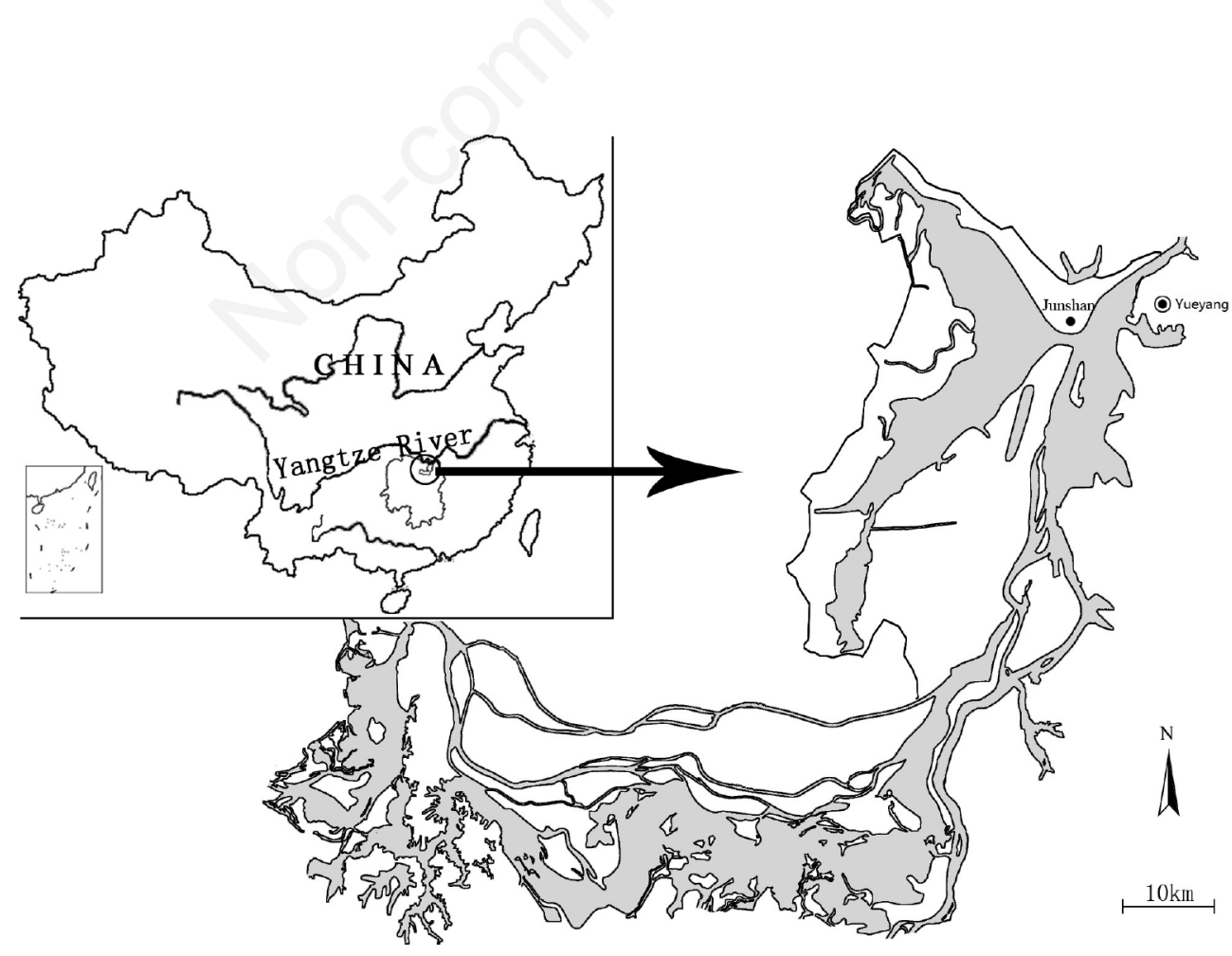

Fig. 1. Location map of Dongting Lake, China. 
cipitation is $1382 \mathrm{~mm}$, with more than $60 \%$ falling between April and August. This lake is characterized by large seasonal fluctuations in water level; it is completely flooded during May-October and drained during November-April. In this lake, wetland plants usually distribute along the water-level gradient (high-elevation species Miscanthus sacchariflorus (Maxim.) Benth, middle-elevation species C. brevicuspis and P. hydropiper, and low-elevation species Phalaris arundinacea Linn). Typically, C. brevicuspis forms large patches of mono-dominant communities or is co-dominated with other Carex species or P. hydropiper, while $P$. hydropiper is usually co-dominate with Carex species (Peng et al., 1984).

In recent years, particularly after construction of the Three Gorge Dam, the structure of plant communities has changed significantly in the Dongting Lake (Li et al., 2013). We (staff of Dongting Lake Station for Wetland Ecosystem Research, Chinese Academy of Sciences) found that large areas of $P$. hydropiper have disappeared during our annual field investigations. However, the mechanism of $P$. hydropiper loss is far from clear.

\section{Plant materials}

C. brevicuspis, a perennial rhizomatous sedge, is a widespread wetland species found in eastern mainland China and Taiwan (Dai et al., 2010). The pseudoculm of the plant, made up of a series of overlapping leaf sheaths, is usually $20-55 \mathrm{~cm}$ in height. $P$. hydropiper (Polygonaceae) was described as a cosmopolitan annual herb ( $\mathrm{Li}$ et al., 2013). The leaves of P. hydropiper tend to be wavy at the edges, and the plant often has a reddish appearance. Fibrous roots usually grow on the internodes of belowground rhizomes (Hobbs, 1992). At the Dongting Lake, the two species flower and fruit from April to May before flooding occurs, and both recruit mainly through producing vegetative ramets emerging from underground rhizomes (Chen et al., 2011; Li et al., 2014).

Plants (C. brevicuspis and P. hydropiper) were collected in February, 2011 from Junshan County (112 $59^{\prime} 40.0^{\prime \prime} \mathrm{E} ; 2^{\circ} 22^{\prime} 17.7^{\prime \prime} \mathrm{N}$; East Dongting Lake) extracting small blocks of colonized sediments (20 $\mathrm{cm} \times 20 \mathrm{~cm}$ ), which were subsequently transported to an experimental field in the Institute of Subtropical Agriculture (at the Chinese Academy of Sciences). Plant fragments with roots were placed into plastic buckets, filled with a $15-\mathrm{cm}$ sediment layer (collected from a mixed community of $P$. hydropiper and C. brevicuspis, containing $1.45 \%$ organic matter, $4.04 \mu \mathrm{g} \mathrm{g}^{-1}$ exchangeable $\mathrm{N}$, and $0.88 \mu \mathrm{g} \mathrm{g}^{-1}$ exchangeable $\mathrm{P}$ ) to favor the development of new ramets. The plastic buckets were placed in an outdoor area under natural light and the plants were watered with tap water (containing $0.511 \mu \mathrm{g}$ $\mathrm{L}^{-1} \mathrm{NH}_{4}{ }^{+}-\mathrm{N}, 1.760 \mu \mathrm{g} \mathrm{L}{ }^{-1} \mathrm{NO}_{3}{ }^{-} \mathrm{N}$ and $0.527 \mu \mathrm{g} \mathrm{L}^{-1} \mathrm{PO}_{4}{ }^{3+}-$ $\mathrm{P}, \mathrm{pH}=7.2$ ) when necessary.

\section{Experimental set-up}

The experiment combined two water levels ( 0 and -40 $\mathrm{cm}$ ) with three $C$. brevicuspis densities (no neighboring plants, 0 plants $\mathrm{m}^{-2}$, medium neighbor density, 400 plants $\mathrm{m}^{-2}$, and high neighbor density, 1600 plants $\mathrm{m}^{-2}$ ) in a factorial design with four replicates, according to our field investigation (density ranged from 300-2000 plants $\mathrm{m}^{-2}$ ). Therefore, the experiment included six treatments: two single-individual treatments (one plant of $P$. hydropiper per water level) and four mixed-species treatments (one plant of $P$. hydropiper as the target plants, and 25 plants or 100 plants of $C$. brevicuspis arranged in a $25 \mathrm{~cm} \times 25$ $\mathrm{cm}$ square array as the neighboring plants per water level). A total of 1024 ramets (24 for P. hydropiper and 1000 for C. brevicuspis) of similar size (3-4 leaves, about $25 \mathrm{~cm}$ in height for $C$. brevicuspis and 6-7 leaves, about $23 \mathrm{~cm}$ in height for $P$. hydropiper) were cut from plant cultures on $8^{\text {th }}$ June, 2011. They were planted in PVC tubes $(45 \mathrm{~cm}$ in height and $30 \mathrm{~cm}$ in diameter) filled with $45 \mathrm{~cm}$ of the same soil used for plant incubation.

Six tubes (one tube per treatment) were placed into each of four larger plastic bins $(98 \mathrm{~cm} \times 76 \mathrm{~cm} \times 68 \mathrm{~cm})$ to control water level. The plastic bins were placed in an outdoor area under natural light in the Institute of Subtropical Agriculture, the Chinese Academy of Sciences (Changsha, Hunan province). Different water levels were obtained by elevating the PVC tubes with cement bricks. Experimental treatments began 7 days after planting and two water levels were used: $-40 \mathrm{~cm}$ (drained treatment design based on our field investigation, relative to the soil surface) and $0 \mathrm{~cm}$ (waterlogged treatment, relative to the soil surface). The water table of $P$. hydropiper was $59 \pm 9 \mathrm{~cm}$ during our 2 years field investigation (unpublished data). Tap water was timely supplied and surplus water was removed after rains to control water level. We also replenished the water once a week to prevent algae growth.

The plants were harvested following 3-months of treatment. Plant roots were carefully dug out by hand and cleaned with tap water. First, the longest root length, an important index that reflects the plants ability to acclimatize to changes in water availability, was measured using a $0.1 \mathrm{~cm}$ ruler (Xie et al., 2008). Next, plants were divided into leaves, shoots, and below-ground parts (rhizomes and roots), oven dried at $80^{\circ} \mathrm{C}$ for $48 \mathrm{~h}$, and weighed. Biomass accumulation was calculated as the collective mass of all tissues. Leaf mass fraction, stem mass fraction, and below-ground mass fraction were determined as the ratios of leaf mass, stem mass and below-ground mass to biomass accumulation, respectively.

\section{Relative neighbor effect index}

Intensity of interspecific competition was quantified 
using the relative neighbor effect index (RNE; Markham and Chanway, 1996):

$\mathrm{RNE}=\left(\mathrm{P}_{-\mathrm{N}}-\mathrm{P}_{+\mathrm{N}}\right) / \mathrm{X}$

where $\mathrm{P}$ is the final biomass in the presence $(+\mathrm{N})$ and absence $(-\mathrm{N})$ of neighbors, and $\mathrm{X}$ the larger value of $\mathrm{P}_{-\mathrm{N}}$ or $\mathrm{P}_{+\mathrm{N}}$. Moreover, we also calculated the below-ground relative neighbor effect (BRNE) and the above-ground relative neighbor effect (ARNE) based on the final below-ground mass and above-ground mass, respectively. Calculations were performed using $\operatorname{Ln}(\mathrm{x}+1)$-transformed biomass data (Belcher et al., 1995). RNE is an improved version of the relative competitive intensity index (Wilson and Keddy, 1986; Belcher et al., 1995). The RNE enables both competitive and facilitative interactions to be quantified without bias on a scale of -1 to +1 . A value of 0 indicates no interaction, a negative value indicates facilitation, and a positive value indicates competition. However, the RNE measures the outcome of competition without regard to habitat or environmental conditions (Wilson, 2007).

\section{Data analysis}

Two-way ANOVAs, with water level and neighbor plant density as the main factors, were performed to determine the main effects and interactions on the biomass accumulation, RNE, BRNE and ARNE of $C$. brevicuspis on $P$. hydropiper, biomass allocation, and the longest root length of $P$. hydropiper. Multiple comparisons of means were performed by Tukey's test at the 0.05 significance level and a Bonferroni correction for multiple comparisons was made where necessary. Data were $\log _{10}$-transformed if necessary to reduce heterogeneity of variance. Normality and homogeneity were tested using Liljefors test and Levene's test, respectively. All analyses were performed using the software SPSS 16.0 for Windows (SPSS Inc., USA).

\section{RESULTS}

Both water level $(\mathrm{P}<0.05 ; \mathrm{F}=27.896$; Fig. 2$)$ and $C$. brevicuspis density $(\mathrm{P}<0.05 ; \mathrm{F}=46.128$; Fig. 2$)$ had a significant effect on the biomass accumulation of $P$. hydropiper, which was highest in the $-40 \mathrm{~cm}$ water level + no neighboring plants treatment $(40.5 \pm 1.73 \mathrm{~g}$ per plant) and lowest in the $0 \mathrm{~cm}$ water level + high neighbor density treatment ( $7.6 \pm 1.79 \mathrm{~g}$ per plant). Moreover, biomass accumulation of $P$. hydropiper decreased significantly with increments of $C$. brevicuspis density in the waterlogged treatments. However, in the drained treatments, biomass accumulation of $P$. hydropiper had similar patterns at the medium and high $C$. brevicuspis densities.

The ARNE $(\mathrm{P}<0.05 ; \mathrm{F}=5.262$; Fig. 3$)$ and $\mathrm{RNE}$
$(\mathrm{P}<0.05$; $\mathrm{F}=13.734$; Fig. 3 ) of C. brevicuspis on P. hydropiper were significantly affected by $C$. brevicuspis density. However, both $C$. brevicuspis density $(\mathrm{P}>0.05$; $\mathrm{F}=0.001 ;$ Fig. 3 ) and water level ( $\mathrm{P}>0.05 ; \mathrm{F}=2.440 ;$ Fig. 3$)$ had an insignificant influence on the BRNE of C. brevicuspis on P. hydropiper. In the waterlogged treatment, the ARNE and RNE of C. brevicuspis on P. hydropiper increased significantly along with enhanced density. However, the effect of $C$. brevicuspis density on the ARNE $(\mathrm{P}>0.05 ; \mathrm{F}=0.050 ;$ Fig. 3$)$ and $\mathrm{RNE}(\mathrm{P}>0.05 ; \mathrm{F}=0.406$; Fig. 3) of C. brevicuspis on P. hydropiper was insignificant in the drained treatment. The below-ground mass fraction of $P$. hydropiper was significantly influenced by water level $(\mathrm{P}<0.05 ; \mathrm{F}=7.675 ;$ Tab. 1$)$ and $C$. brevicuspis density $(\mathrm{P}<0.05 ; \mathrm{F}=5.895$; Tab. 1). At the same C. brevicuspis density, the below-ground mass fraction of $P$. hydropiper was significantly higher in the waterlogged treatment than in the drained one, especially with no $C$. brevicuspis treatment. The leaf mass fraction of $P$. hydropiper was only affected by water level $(\mathrm{P}<0.05$; $\mathrm{F}=30.238$; Tab. 1), which was much higher in the drained treatment than in the waterlogged one. The stem mass fraction of $P$. hydropiper was insignificantly influenced by both water level $(\mathrm{P}>0.05 ; \mathrm{F}=2.724 ;$ Tab. 1$)$ and C. brevicuspis density $(\mathrm{P}>0.05 ; \mathrm{F}=2.525 ;$ Tab. 1$)$.

The longest root length of $P$. hydropiper was much shorter in the waterlogged treatment $(15.3-20.0 \mathrm{~cm})$ than in the drained one $(37.3-42.0 \mathrm{~cm} ; \mathrm{P}<0.05 ; \mathrm{F}=37.364$; Fig. 4). However, the effect of density was insignificant ( $\mathrm{P}>0.05 ; \mathrm{F}=0.848$; Fig. 4).

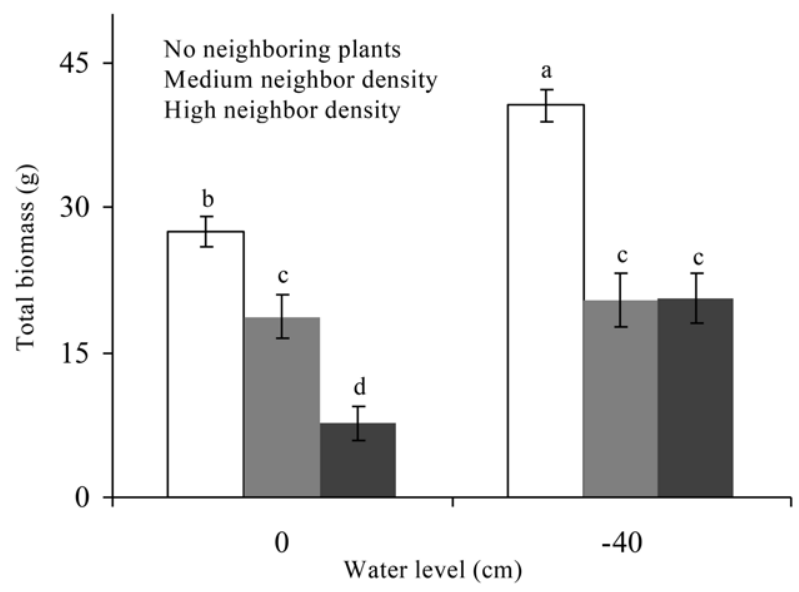

Fig. 2. Biomass accumulation (means $\pm \mathrm{SE}, \mathrm{n}=4$ ) of Polygonum hydropiper growing under three Carex brevicuspis densities (no neighboring plants, 400 plants $\mathrm{m}^{-2}, 1600$ plants $\mathrm{m}^{-2}$ ) and two water levels $(0 \mathrm{~cm}$ and $-40 \mathrm{~cm}$, waterlogged and drained conditions). Different letters indicate significant differences between treatments at the 0.05 significance level. 


\section{DISCUSSION}

When individual $P$. hydropiper were planted, a lower biomass accumulation was recorded in the drained treatments than in the waterlogged treatment. This observation

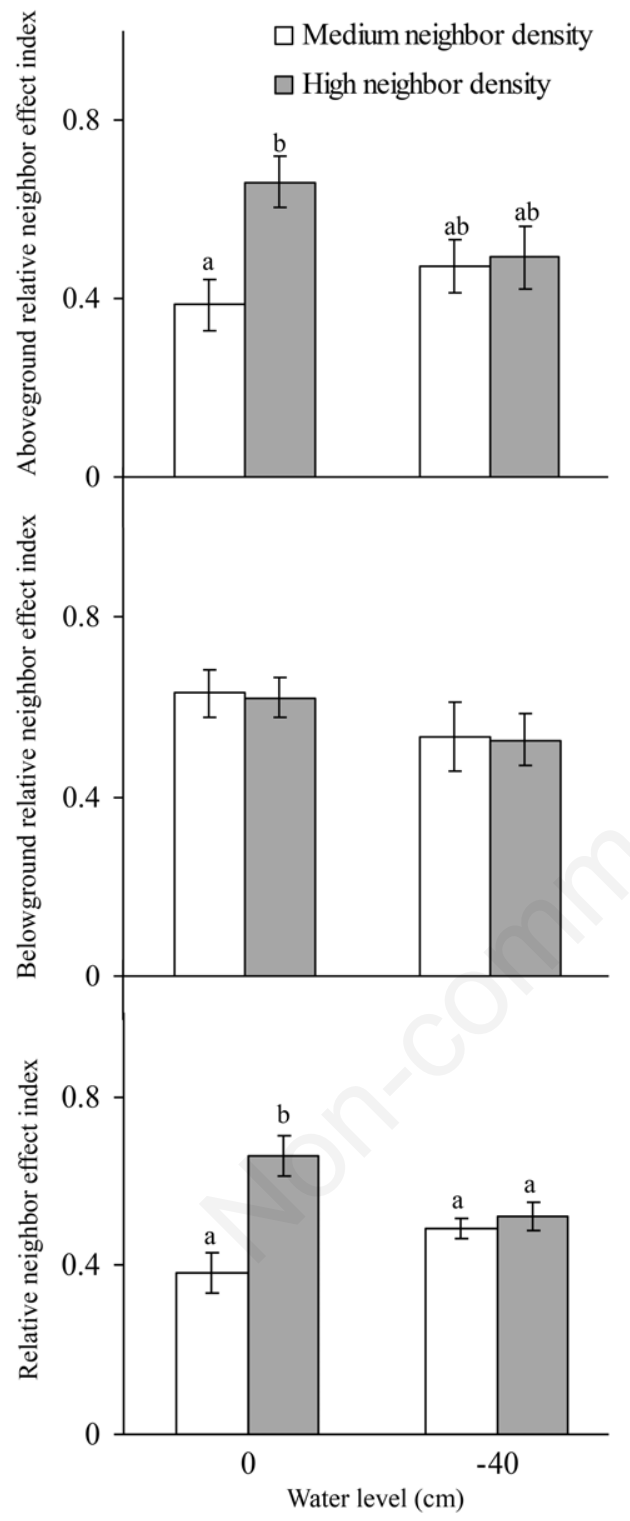

Fig. 3. Aboveground relative neighbor effect index (ARNE, means $\pm \mathrm{SE}, \mathrm{n}=4$ ), belowground relative neighbor effect index (BRNE, means $\pm \mathrm{SE}, \mathrm{n}=4$ ), and relative neighbor effect index (RNE, means \pm SE, $n=4$ ) of Polygonum hydropiper growing under different Carex brevicuspis densities (no neighboring plants, 400 plants $\mathrm{m}^{-2}, 1600$ plants $\left.\mathrm{m}^{-2}\right)$ and two water levels $(0 \mathrm{~cm}$ and -40 $\mathrm{cm}$, waterlogged and drained conditions). Different letters indicate significant differences between treatments at the 0.05 significance level. ARNE, BRNE, and RNE were calculated based on the final aboveground biomass, belowground biomass, and total biomass in the presence and absence of neighbors, respectively. suggests that the growth of $P$. hydropiper was significantly inhibited by waterlogging. This is consistent with our first hypothesis: P. hydropiper is an annual species that can grow in terrestrial or shallow flooded habitats such as riverbanks, stream sides, and wet valleys. Furthermore, it might growth better in elevated areas than in shallowflooded habitats (Li et al., 2013). Actually, sediment waterlogging has long been identified as a major abiotic stress and the constraints it imposes on roots have marked effects on plant growth and development (Parent et al., 2008).

Our data support the idea that during long-term evolutionary acclimatization, $P$. hydropiper might have been acclimatized to waterlogging stress through its morphological and physiological adaptations, such as decreased root length and altered biomass allocation patterns. Indeed, our study verified that the longest root length of $P$. hydropiper recorded at the waterlogged treatment was significantly lower than that measured in the drained treatments. This is probably a response to sediment anoxia/hypoxia in agreement with those observed by Xie et al. (2008). Shorter root length is beneficial for plant survival and maintains root activity under water-saturated environments, since the top layer of sediment usually has higher oxygen contents and Eh values (Wheeler, 1999; Xie et al., 2008). Moreover, our results also confirm that the below-ground mass fraction was much higher in the waterlogged treatments than in drained treatments. In waterlogged sediments, roots of both tolerant and intolerant species may serve as a carbohydrate sink and thus inhibit the investment in the above-ground plant organs (Lenssen et al., 2003), which might be beneficial to plants in preventing oxygenation of the entire root system, as has been

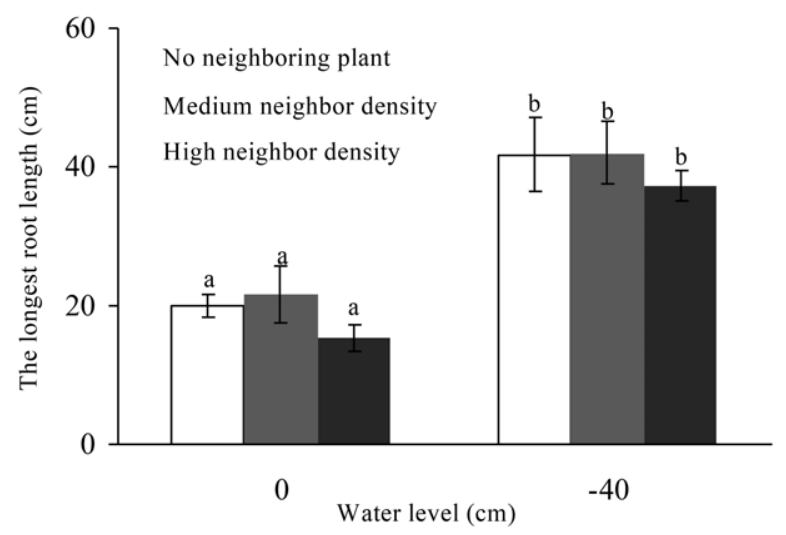

Fig. 4. The longest root length (means $\pm \mathrm{SE}, \mathrm{n}=4$ ) of Polygonum hydropiper growing under three Carex brevicuspis densities (no neighboring plants, 400 plants $\mathrm{m}^{-2}, 1600$ plants $\mathrm{m}^{-2}$ ) and two water levels $(0 \mathrm{~cm}$ and $-40 \mathrm{~cm}$, waterlogged and drained conditions). Different letters indicate significant differences between treatments at the 0.05 significance level. 
Tab. 1. Biomass allocation (means \pm SE, $n=4$ ) of Polygonum hydropiper growing under three Carex brevicuspis densities (no neighboring plants, 400 plants $\mathrm{m}^{-2}$, and 1600 plants $\left.\mathrm{m}^{-2}\right)$ and two water levels $(0 \mathrm{~cm}$ and $-40 \mathrm{~cm}$, waterlogged and drained conditions).

\begin{tabular}{lcccc} 
Water level $(\mathrm{cm})$ & C. brevicuspis densities $\left(\right.$ plants $\left.\mathrm{m}^{-2}\right)$ & Leaf mass fraction & Stem mass fraction & Below - ground mass fraction \\
0 & 0 & $32.16 \pm 3.98^{\mathrm{b}}$ & $33.22 \pm 2.77^{\mathrm{ab}}$ & $34.62 \pm 1.27^{\mathrm{a}}$ \\
0 & 400 & $31.68 \pm 1.23^{\mathrm{b}}$ & $42.08 \pm 4.85^{\mathrm{a}}$ & $26.24 \pm 3.82^{\mathrm{bc}}$ \\
\hline 0 & 1600 & $28.10 \pm 1.58^{\mathrm{b}}$ & $39.57 \pm 2.37^{\mathrm{ab}}$ & $32.33 \pm 1.25^{\mathrm{ab}}$ \\
-40 & 0 & $39.81 \pm 0.38^{\mathrm{a}}$ & $33.97 \pm 0.97^{\mathrm{ab}}$ & $26.22 \pm 0.62^{\mathrm{bc}}$ \\
\hline-40 & 400 & $41.16 \pm 1.64^{\mathrm{a}}$ & $36.76 \pm 1.02^{\mathrm{ab}}$ & $22.08 \pm 2.52^{\mathrm{c}}$ \\
-40 & 1600 & $38.44 \pm 1.05^{\mathrm{a}}$ & $32.79 \pm 0.90^{\mathrm{b}}$ & $28.77 \pm 1.78^{\mathrm{abc}}$ \\
\hline
\end{tabular}

${ }^{a-c}$ Different letters indicate significant difference among treatments at the 0.05 significance level.

previously reported byVisser et al. (2000). However, our results contradict, in part, to the results of Kalapos et al. (1996), which found that plant root could be stimulated to grow under soil drying conditions. The difference might be accounted for by different water availabilities. In our experiment, water was not a limiting factor influencing the growth of $P$. hydropiper due to its higher root length in the drained treatment. Therefore, a higher root mass fraction was not observed in the drained treatment.

The relationship between interspecific competition and plant growth has been widely examined and showed that increased densities could reduce plant growth due to lower resource availability (Grace and Tilman, 1990; Davis et al., 2009). In this study, biomass accumulation of $P$. $h y$ dropiper decreased significantly along with increasing $C$. brevicuspis densities in waterlogged treatments. Moreover, the ARNE and RNE of C. brevicuspis on P. hydropiper also increased significantly with increasing $C$. brevicuspis densities in the waterlogged treatments. These results are consistent with our second hypothesis, and suggest that a higher C. brevicuspis density intensifies competition for light and available growth space in the waterlogged treatment. Consequently, a limited growth of $P$. hydropiper was observed, in agreement with those suggested from previous studies (Davis et al., 2009; Luo et al., 2010). However, similar BRNE patterns at different $C$. brevicuspis densities suggested that competition between $C$. brevicuspis to $P$. hydropiper is mainly associated with light competition rather than with nutrient availability.

Similar biomass accumulation, ARNE, BRNE, and RNE at different $C$. brevicuspis densities in the drained treatments suggest that the intensity of competition was reduced in the drained condition In fact, plant competition that is dependent on the intensity of environmental stress has been long studied by ecologists (Brooker et al., 2008; Luo et al., 2010). Luo et al. (2010) found that the intensity of intra- and interspecific competition decreased, while the intensity of facilitation increased, with increasing water levels among three typical marsh plants in the Sanjiang Plain. The higher sensitivity of C. brevicuspis to water availability compared to P. hydropiper might ex- plain the growth performance of the latter in the drained treatment (Li et al., 2013). During 7 years of field investigation, we (the researchers in the Dongting Lake Station for Wetland Ecosystem Research, the Chinese Academy of Sciences) found that the maximum root depth of C. brevicuspis was less than $20 \mathrm{~cm}$. Therefore, the growth of $C$. brevicuspis might be significantly limited at the $-40 \mathrm{~cm}$ water level, consequently, resulting in lower levels of competition with $P$. hydropiper. At the end of the experiment, we also found that many $C$. brevicuspis leaves were withered, which led to reduced interspecific competition for light, supported by the above-ground relative neighbor effect as occurred in the drained treatment.

\section{CONCLUSIONS}

In conclusion, our study confirmed that the intensity of competition between $C$. brevicuspis to $P$. hydropiper increased along with increasing $C$. brevicuspis density in the waterlogged treatment, while there was no significant change between the two C. brevicuspis densities in the drained treatment. Moreover, our study also suggested that $P$. hydropiper could acclimate to waterlogged stress by modulating its root architecture, such as reducing the root system length or increasing the root mass fraction. In recent years, the $P$. hydropiper community has been seriously degraded in association with the changing hydrological regimes in the Dongting Lake, leading to a significant reduction of biodiversity in the lake. In this context, present data provide experimental information on the role of competition in structuring the dynamics of wetland plant communities and may assist with the effective management of regulated lakes or reservoirs such as the Dongting Lake.

\section{ACKNOWLEDGMENTS}

The authors greatly appreciate B. H. Pan for help with the experiment management and plant harvest. This study was supported by the National Key Technology Research and Development Program of China (2014BAC09B03), National Basic Research Program of China (2012CB 
417005), the National Natural Science Foundation of China (31200271), the Science and Technology Project of Hunan Province (2014NK2009), and the Knowledge Innovation Program of the Chinese Academy of Sciences (ISACX-LYQY-QN-1208).

\section{REFERENCES}

Armas C, Pugnaire FI, 2005. Plant interactions govern population dynamics in a semi-arid plant community. J. Ecol. 93:978-989.

Belcher JW, Keddy PA, Twolan-Strutt L, 1995. Root and shoot competition intensity along a soil depth gradient. J. Ecol. 83:673-682.

Brooker RW, Maester FT, Callaway RM, Lortie CL, Cavieres LA, Kunstler G, Liancourt P, Tielbörger K, Travis JMJ, Anthelme F, Armas C, Coll L, Corcket E, Delzon S, Forey E, Kikvidze Z, Olofsson J, Pugnaire F, Quiroz CL, Saccone P, Schiffers K, Seifan M, Touzard B, Michalet R, 2008. Facilitation in plant communities: the past, the present, and the future. J. Ecol. 96:18-34.

Callaway RM, Brooker RW, Choler P, Kikvidze Z, Lortie CJ, Michalet R, Paolini L, Pugnaire FI, Newingham B, Aschehoug ET, Armas C, Kikodze D, Cook BJ, 2002. Positive interactions among alpine plants increase with stress. Nature 417:844-848.

Chen XS, Xie YH, Deng ZM, Li F, Hou ZY, 2011. A change from phalanx to guerrilla growth form is an effective strategy to acclimate to sedimentation in a wetland sedge species Carex brevicuspis (Cyperaceae). Flora 206:347-350.

Dai LK, Liang SY, Zhang SR, Tang YC, Koyama T, Tucker GC, Simpson DA, Noltie HJ, Strong MT, Bruhl JJ, Wilson KL, Muasya AM, 2010. Flora of China. Vol. 23 (Cyperaceae). Science Press, Beijing, and Missouri Botanical Garden Press, St. Louis.

Davis CA, Bidwell JR, Hickman KR, 2009. Effects of hydrological regimes on competitive interactions of Schoenoplectus fluviatilis and two co-occurring wetland plants. Aquat. Bot. 91:267-272.

Deegan BM, White SD, Ganf GG, 2007. The influence of water level fluctuations on the growth of four emergent macrophyte species. Aquat. Bot. 86:309-315.

Franks SJ, Peterson CJ, 2003. Burial disturbance leads to facilitation among coastal dune plants. Plant. Ecol. 168:13-21.

Gebauer RLE, Schwinning S, Ehleringer JR, 2002. Interspecific competition and resource pulse utilization in a cold desert community. Ecology 83:2002-2616.

Grace JB, 1999. The factors controlling species density in herbaceous plant communities: an assessment. Perspect. Plant. Ecol. 2:1-28.

Grace JD, Tilman D, 1990. Perspective on plant competition. Academic Press, San Diego: 484 pp.

Grime JP, 2001. Plant strategies, vegetation processes, and ecosystem properties. J. Wiley \& Sons, Chichester: 417 pp.

Gross N, Liancourt P, Choler P, Suding KN, Lavorel S, 2010. Strain and vegetation effects on local limiting resources explain the outcome of biotic interactions. Perspect. Plant Ecol. Evol. Syst. 12:9-19.

Hobbs CH, 1992. Occurrence and distribution of Polygonum species in Ohio. Ohio J. Sci. 92:88-97.
Kalapos T, van den Boogaard R, Lambers H, 1996. Effects of soil drying on growth, biomass allocation and leaf gas exchange of two annual grass species. Plant Soil. 185:137-149.

Lenssen JPM, Mentin FBJ, van der Putten WH, 2003. Plant responses to simultaneous stress of waterlogging and shade: amplified or hierarchical effects? New Phytol. 157:281-290.

Li F, Li YZ, Qin HY, Xie YH, 2011. Plant distribution can be reflected by the different growth and morphological responses to water level and shade in two emergent macrophyte seedlings in the Sanjiang Plain. Aquat. Ecol. 45:89-97.

Li F, Qin XY, Xie YH, Chen XS, Hu JY, Liu YY, Hou ZY, 2013. Physiological mechanisms for plant distribution pattern: responses to flooding and drought in three wetland plants from Dongting Lake, China. Limnology 14:71-76.

Li F, Xie YH, Tang Y, Liu YY, Chen XS, Deng ZM, Hu JY, Liu N, 2014. Negative influence of burial stress on plant growth was ameliorated by increased plant density in Polygonum hydropiper. Limnologica 45:33-37.

Lortie CJ, Callaway RM, 2006. Re-analysis of meta-analysis: Support for the stress-gradient hypothesis. J. Ecol. 94:7-16.

Loreti J, Oesterheld M, 1996. Intraspecific variation in the resistance to flooding and drought in populations of Paspalum dilatatum from different topographic positions. Oecologia 108:279-284.

Luo WB, Xie YH, 2009. Growth and morphological responses to water level and nutrient supply in three emergent macrophyte species. Hydrobiologia 624:151-160.

Luo WB, Xie YH, Chen XS, Li F, Qin XY, 2010. Competition and facilitation in three marsh plants in response to a waterlevel gradient. Wetlands 30:525-530.

Maestre FT, Valladares F, Reynolds JF, 2005. Is the change of plant-plant interactions with abiotic stress predictable? A meta-analysis of field results in arid environments. J. Ecol. 93:748-757.

Markham JH, Chanway CP, 1996. Measuring plant neighbor effects. Functional Ecol. 10:548-549.

Mesléard F, Ham LT, Boy V, van Wijck C, Grillas P, 1993. Competition between an introduced and an indigenous species: the case of Paspalum paspalodes (Michx) Schribner and Aeluropus littoralis (Gouan) in the Camargue (southern France). Oecologia 94:204-209.

Michalet R, Brooker RW, Cavieres LA, Kikvidze Z, Lortie CJ, Pugnaire FI, Valiente-Banuet A, Callaway RM, 2006. Do biotic interactions shape both sides of the humped-back model of species richness in plant communities? Ecol. Lett. 9:767-773.

Pagter M, Bragato C, Brix H, 2005. Tolerance and physiological responses of Phragmites australis to water deficit. Aquat. Bot. 81:285-299.

Parent C, Capelli N, Berger A, Crèvecoeur M, Dat JF, 2008. An overview of plant responses to soil waterlogging. Plant Stress 2:20-27.

Pan Y, Xie YH, Deng ZM, Tang, Y, Pan, DD, 2014. High water level impedes the adaptation of Polygonum hydropiper to deep burial: responses of biomass allocation and root morphology. Sci. Rep. 4:5612.

Peng D, Yuan Z, Peng G, Tang C, Liao Q, 1984. [Characteristics and distribution patterns of the vegetation in the Dongting Lake region, Hunan Province].[Article in Chinese]. J. Central-South Forest Coll. 4:110-119. 
Pennings SC, Seling ER, Houser LT, Bertness AM, 2003. Geographic variation in positive and negative interactions among salt marsh plants. Ecology 84:1527-1538.

Ribaudo C, Bartoli M, Racchetti E, Longhi D, Viaroli P, 2011. Seasonal fluxes of $\mathrm{O}_{2}$, DIC and $\mathrm{CH}_{4}$ in sediments with $\mathrm{Val}$ lisneria spiralis: indications for radial oxygen loss. Aquat. Bot. 94:134-142.

Soana E, Bartoli M, 2014. Seasonal regulation of nitrification in a rooted macrophyte (Vallisneria spiralis L.) meadow under eutrophic conditions. Aquat. Ecol. 48:11-21.

Visser EJW, Colmer TD, Blom CWPM, Voesenek LACJ, 2000. Changes in growth, porosity, and radial oxygen loss from adventitious roots of selected mono- and dicotyledonous wetland species with contrasting types of aerenchyma. Plant Cell Environ. 23:1237-1245.

Weigelt A, Röttgermann M, Steinlein T, Beyschlag W, 2000. Influence of water availability on competitive interactions be- tween plant species on sandy soils. Folia Geobotanica 35:169-178

Wilson MV, 2007. Measuring the components of competition along productivity gradients. J. Ecol. 95:301-308.

Wilson SD, Keddy PA, 1986. Species competitive ability and position along a natural stress/disturbance gradient. Ecology 67:1236-1242.

Wheeler BD, 1999. Water and plants in freshwater wetlands, p. 127-180. In: A.J. Baird and R. Wilby (eds.), Eco-hydrology: plants and water in terrestrial and aquatic environments. Routledge, London.

Xie YH, Luo WB, Wang KL, Ren B, 2008. Root growth dynamics of Deyeuxia angustifolia seedlings in response to water level. Aquat. Bot. 89:292-296.

Zhang XH, Mao R, Gong C, Yang GS, Lu YZ, 2014. Effects of hydrology and competition on plant growth in a freshwater marsh of northeast China. J. Freshwater Ecol. 29:117-127. 